\title{
VIOLÊNCIA DE GÊNERO, CULTURA DO ESTUPRO E SAÚDE PÚBLICA: UMA ANÁLISE SEM RECORTE
}

\author{
GENDER VIOLENCE, RAPE CULTURE AND PUBLIC HEALTH: AN NON-CUT \\ ANALYSIS
}

\author{
VIOLENCIA DE GÉNERO, CULTURA DE VIOLACIÓN Y SALUD PÚBLICA: UN \\ ANÁLISIS SIN CORTE
}

\author{
Bianca Mazagão \\ Lusanir de Sousa Carvalho ii
}

\begin{abstract}
Resumo: Este trabalho teve por tema principal o exame da cultura do estupro, enquanto prática social, à luz das questões de gênero e dos preceitos da Saúde Coletiva, com o entendimento da dimensão de gênero não como recorte, mas como um instrumental de análise dos fenômenos e dos sujeitos em sua complexidade social, decorrente de uma dominação colonial e patriarcal. Nesse sentido, questionou-se se a perspectiva de gênero influencia a manutenção e transmissão de práticas culturais violentas e de que forma os programas de saúde existentes no Brasil problematizam essas questões.Os resultados encontrados ressaltam a importância dos psicólogos analisarem criticamente seus referenciais teóricos durante a condução da prática clínica, bem como a sociedade em geral, se questionar como cada um pode estar reforçando essa lógica estrutural e como os dispositivos de saber/poder (ciências sociais/ Estado) participam da construção e manutenção dessas práticas.
\end{abstract}

\begin{abstract}
This work had as its main theme the examination of the culture of rape, as a social practice, in the light of gender issues and the precepts of Collective Health, with the understanding of the gender dimension not as an outline, but as an instrument of analysis of the phenomena and subjects in their social complexity, resulting from colonial and patriarchal domination. In this sense, it was questioned whether the gender perspective influences the maintenance and transmission of violent cultural practices and how the existing health programs in Brazil problematize these issues. The results found underline the importance of the psychologists critically analyze their theoretical references during the conduct of clinical practice, as well as society in general, ask yourself how much each one can be reinforcing this structural logic, to whom it benefits and how the knowledge devices/power (social sciences/state) participate in the construction and maintenance of these practices.
\end{abstract}

Resumen: Este trabajo tuvo como tema principal el examen de la cultura de la violación, como práctica social, a la luz de los problemas de género y los preceptos de la salud colectiva, con la comprensión de la dimensión de género no como un esquema, sino como un instrumento de análisis de los fenómenos y de sujetos en su complejidad social, resultante de la dominación colonial y patriarcal. En este sentido, se cuestionó si la perspectiva de género influye en el mantenimiento y la transmisión de prácticas culturales violentas y cómo los programas de salud existentes en Brasil problematizan estos problemas. Los resultados encontrados subrayan la importancia de los psicólogos para analizar críticamente sus referencias teóricas durante la realización de la práctica clínica, así como la sociedad en general, para cuestionar cuánto puede cada uno reforzar esta lógica estructural, a quién beneficia y cómo los dispositivos de conocimiento/power (ciencias sociales/Estado) participa en la construcción y mantenimiento de estas prácticas.

Palavras-chaves:Cultura do estupro. Feminismo. Psicologia. Saúde Coletiva.

Keywords: Rape culture. Feminism. Psychology. Collective Health.

Palabras clave: Cultura de violación. Feminismo. Psicología Salud pública. 


\section{INTRODUÇÃO}

O interesse dos pesquisadores por uma abordagem comportamental da cultura, por estudos de gênero e de violência contra as mulheres voltou à atenção da comunidade científica para a tentativa de compreender como esses conceitos se relacionam com a psicologia, ou de como a clínica psicológica pode ser também orientada pela perspectiva feminista. Nesse caso, o feminismo, como tendência teórica inovadora, de forte potencial crítico e político auxilia o enfrentamento da violência contra mulher, instalada de forma estrutural em nossa sociedade (ALVES, 2013).

Dados como os do Fórum Brasileiro de Segurança Pública (FBSP, 2019) mostram que aproximadamente 4,6 milhões de mulheres foram tocadas ou agredidas fisicamente por motivos sexuais no país, uma média de nove por minuto. Tal fato aponta que nossa cultura vem sendo permissiva ao longo da história e que as práticas culturais que permitem e reforçam essa violência continuam a ser transmitidas entre sucessivas gerações.

Este trabalho teve por tema principal o exame da cultura do estupro, enquanto prática social, à luz das questões de gênero e dos preceitos da Saúde Coletiva, com o entendimento da dimensão de gênero não como recorte, mas como um instrumental de análise dos fenômenos e dos sujeitos em sua complexidade social, decorrente de uma dominação colonial e patriarcal.

Nesse sentido, a proposta deste artigo foi analisar as contribuições da Psicologia, no que diz respeito à cultura do estupro, dentro da perspectiva biopsicossocial para a promoção de saúde em seus vários aspectos. Pode-se dizer que as questões de gênero influenciam a manutenção e transmissão de práticas culturais violentas? Os programas de prevenção e promoção da saúde existentes no Brasil problematizam questões feministas e de gênero?

O objetivo geral foi analisar as contribuições da intervenção psicológica, no âmbito da saúde, no que diz respeito à Cultura do Estupro. Os objetivos específicos foram: (i) discutir o conceito de Práticas Culturais e Cultura do Estupro; (ii) articular esses conceitos com as análises obtidas dos programas de Prevenção e Promoção da Saúde; (iii) identificar se estes programas incluem problematizações de gênero - pela necessidade de contextualização sócio histórica do cenário atual.

A metodologia utilizada para atingir os escopos pretendidos neste trabalho envolveu o método hipotético-dedutivo e a promoção de uma pesquisa exploratória de gabinete, por meio de revisão de literatura. A consulta à literatura foi conduzida em páginas da internet como portal Scielo, portal de periódicos da Coordenação de Aperfeiçoamento de 
Pessoal de Nível Superior (CAPES), em busca de artigos, livros e monografias (graduação, pós-graduação lato sensu, dissertações e teses). A escolha da literatura teve como base a questão norteadora desta pesquisa, a hipótese e os objetivos.

A presente pesquisa justifica-se pela importância do estudo dessas práticas que subjugam e violentam mulheres. Assim, busca demonstrar sua construção sócio-histórica, oportunizando a desnaturalização das mesmas ao questionar quem se beneficia e mantém privilégios com a sua transmissão. Faz-se necessário pontuar que assim como algumas práticas podem funcionar como instrumento de controle e regulação dos corpos, as políticas públicas e os programas de prevenção e promoção da saúde podem promover ou violar direitos a depender da forma como são concebidos e/ou executados, o que demanda serem pensados a partir de análises como esta. Estudar esses comportamentos epidêmicos e planejar culturas menos violentas é necessário e urgente, por envolver estatísticas com uma dimensão nada abstrata, que provavelmente está acontecendo agora com alguma mulher, enquanto se lê sobre isso.

\section{REFERENCIAL TEÓRICO CONCEITUAL}

Compreendendo que os processos de adoecimento psíquico são permeados por questões sociais e de gênero, entende-se que a intervenção, seja na forma de psicoterapia ou prevenção, envolve discutir a relevância da perspectiva feminista na problematização de diversas questões que afetam a vida e o adoecimento das pessoas.

Com caminhos marcados por contribuições iluministas, o feminismo surgiu como movimento social no contexto também das ideias das Revoluções Francesa e Americana, em um primeiro momento, em torno da demanda por direitos sociais e políticos, tendo seu auge na luta sufragista. O movimento ressurgiu com nova força e potencial reflexivo nos anos de 1960, com a bandeira de afirmação: “o pessoal é político". Uma verdadeira ruptura epistemológica que significa que a vida pessoal reflete valores e dimensões da cultura, e, da mesma forma, a cultura e esses mesmos valores são também afetados pelas vidas pessoais. Apontou-se, dessa forma, o caráter político da opressão sofrida pelas mulheres que, até então, a vivenciavam isoladamente, de forma individualizada (COSTA, 2006).

Simone de Beauvoir destacou-se como fundadora do feminismo contemporâneo. Considerada como "encarnação da mulher liberada dos constrangimentos da sociedade machista", capaz de trilhar um caminho próprio e de esboçar a promessa de uma nova forma de conjugalidade, mais livre, satisfatória e equilibrada através de sua relação com Jean-Paul Sartre. Sua influência se deveu, sobretudo, a publicação de O Segundo Sexo, em 
1949, que apesar do "substrato psicanalítico do qual, embora ciente da misoginia de Freud, não consegue se livrar" representou uma relevante tentativa de entender a construção social do "feminino" como um conjunto de determinações e expectativas destinado a cercear a autonomia das mulheres. Essa publicação contribuiu, também, para a redefinição das fronteiras da política e indicou uma profunda sobreposição entre o pessoal e o social, abrindo caminho para o provocativo slogan "o pessoal é político". Com a frase "Não se nasce mulher, torna-se mulher" sua obra nega uma definição de mulher pelos seus hormônios ou instintos misteriosos, ou seja, que a mesma só é possível na forma pela qual ela recupera seu corpo e sua relação com o mundo. "A objetificação da mulher, a negação de seu potencial de transcendência e a sua limitação à dimensão da natureza (a ser contida pela cultura), bem como o fato de ser permanentemente levada a se ver pelos olhos dos homens" são questões que orientam a crítica feminista à submissão das mulheres (MIGUEL e BIROLI, 2014, p. 25-26).

As reflexões feministas possibilitaram o surgimento do conceito de gênero. Bourdieu (2002) define gênero como sendo as ações e papéis atribuídos socialmente a homens e mulheres, identificados e compreendidos simbolicamente. Saffioti (1987) afirma que houve uma revisão das questões identitárias e da forma de se pensar as dinâmicas que afetam os processos de saúde e adoecimento, a partir dessa problematização trazida pelo feminismo. A autora destaca, por exemplo, que a correlação desemprego x violência pode ser observada de forma clara por meio dos estudos da violência de gênero, da violência contra as mulheres, da violência doméstica e da violência intrafamiliar. Esse é apenas um dos alertas que ela faz sobre as enfermidades que podem acometer os sujeitos na perspectiva ampliada do conceito de saúde (SAFFIOTI, 2011).

Seguindo essa linha de verificação e revisão das teorias e práticas à luz das problematizações de gênero, Saffioti (2011) aponta que as mulheres são socializadas para desenvolver comportamentos dóceis e apaziguadores enquanto os homens, ao contrário, são estimulados a desenvolver condutas agressivas, perigosas, que revelem força e coragem. Alves (2013) acrescenta que estabelecer "padrões aceitáveis e adequados de comportamento para as pessoas baseados no sexo coloca aqueles que não se enquadram dentro desta 'normalidade' como desviantes", o que pode afetar a saúde mental dessas pessoas. Assim, os psicólogos(as) também devem atuar criticamente diante das relações sociais de gênero, uma vez que tais relações estão associadas com a experiência de sofrimento psíquico, bem como com o tratamento oferecido a esse sofrimento (ZANELLO, 2010). 
A incorporação do conceito relacional de gênero usado para identificar um sistema de signos e símbolos das relações de poder e de hierarquia entre os sexos consolidou-se como uma categoria analítica, indo além da ruptura com um modelo de ciência patriarcal. Isso legitimava uma cultura opressora, sobretudo, transformações nas estruturas sociais. A crítica visão feminista rejeitava uma ciência alicerçada em referentes e valores masculinos e neutros, pois entendia que a mesma estava sempre impregnada de valores culturais e materiais. Criticava também qualquer forma de ciência que se considerasse universal por acreditar que posturas teóricas e o conhecimento em geral somente se constroem em um dado contexto social e cultural específico e transitório (BANDEIRA, 2008).

Com base na ideia supracitada de ruptura a esse ideal de sujeito genérico pode-se elucidar que houve também um avanço no que tange ao reconhecimento da importância da subjetividade do(a) pesquisador(a) em relação ao processo de produção do conhecimento, pois: "a crítica feminista acabou por questionar o androcentrismo ao censurar as formulações teórico-empíricas existentes, e possibilitou ainda uma censura epistemológica às noções de neutralidade e de objetividade"(DESCARRIES, 1994 apud BANDEIRA, 2008, p. 224). Gergen (1993) corrobora essa denúncia que não há neutralidade na ciência e aponta que acreditar ou defender a ciência como isenta de valor é iludir a si mesmo, ou ainda mais sério, iludir os outros. Ele acrescenta ainda que a tentativa de encobrir o caráter político da ciência contribui para a manutenção do status quo da sociedade.

Em paralelo, os estudos pós-coloniais divergem dessa tradição eurocêntrica e, ao falar sobre essa dimensão sociopolítica, lançam luz sobre a necropolítica vigente. A noção de necropolítica, a saber, refere-se à política de "destruição material dos corpos, e, populações humanas julgadas como descartáveis” (MBEMBE, 2012, p. 135), do genocídio de sujeitos matáveis. A análise crítica das construções discursivas sobre neutralidade científica deve questionar quem produz e quem se beneficia (ou se prejudica) com essa lógica e com a regulação e subjugação dos corpos femininos. Apontamos, anteriormente, a relação entre o aprisionamento de comportamentos em repertórios restritos e processos de patologização. Resta a pergunta: Qual a função desse silenciamento às demais vozes e visões de mundo? Quem se beneficia já que, conforme Ribeiro (2017), “os saberes produzidos pelos indivíduos historicamente discriminados, para além de serem contra discursos importantes, são lugares de potência e configuração do mundo por outros olhares e geografias" (RIBEIRO, 2017, p. 43). 
A banalização da reprodução da violência pode ser explicada pelo conceito de Pedagogia da Crueldade, onde as pessoas são ensinadas a não ter empatia para com as vítimas, numa espécie de programação para a baixa sensibilidade em direção ao sofrimento do outro (SEGATO, 2014). Essa desumanização é abordada por Ribeiro (2017), que descreve como Outro do Outro a posição de difícil reciprocidade da mulher negra: "Se para Simone de Beauvoir, a mulher é o Outro, por não ter reciprocidade do olhar do homem, para Grada Kilomba, a mulher negra é o Outro do Outro” (RIBEIRO, 2017, p.23).

Em relação a mescla de situações e de vítimas, como características relativas à idade, raça e classe social a que pertencem, segundo Pasinato (2011) é necessário desagregar as situações de violência contra as mulheres ao invés de "amalgamá-las". Ao dar-lhes algum significado, a partir dos seus contextos, torna-se possível refletir sobre a necessidade de políticas mais pontuais e, ao mesmo tempo, introduzir discussões sobre especificidades de gênero de maneira transversal nas políticas de governo e do Estado. Torna-se, então, mais produtivo explorar as causas e os contextos em que ocorrem para qualificar os eventos e compreender as relações de poder que concorrem para sua prática.

Do mesmo modo, Biroli e Miguel (2015), apontam que uma análise das relações de gênero que não problematize concomitantemente o entrelaçamento das desigualdades de raça e de classe acaba por reduzir seu potencial analítico, assim como seu potencial transformador. O sexismo, segundo os autores, impacta as mulheres de formas diferentes, em graus variáveis e com efeitos que precisam ser analisados contextualmente.

Classificar ou formular tipos violentos instiga não só os pesquisadores, mas também o senso comum. Para muitos, a violência é praticada por indivíduos possuidores de determinadas características: homem portador de algum sofrimento psíquico, ou que seja obsessivo, sempre traído, ou ainda, que por abuso de bebida alcoólica "perderia o controle de seus atos". No entanto, mantém-se a conexão entre ser agressor e ser homem, pela alta frequência em que ocorre. Para entendermos o porquê dos homens serem os principais agressores, seja contra a mulher ou contra outros homens, será preciso apreender o modo como a violência participa da própria formação da identidade masculina, do modo de ser e fazer-se homem (SCHRAIBER et al, 2005).

É necessário compreender a relação entre masculinidade exercitada e a prática da violência cotidiana, que se apresenta para muitos homens como resposta à demanda de desempenho de seu papel social, que é estimulada de diferentes formas durante sua socialização, o que se torna um elemento-chave para a construção de um determinado tipo 
de subjetividade masculina. Determinadas construções culturais elaboram esses valores em termos de comportamentos e atitudes com uma moral muito peculiar, tão peculiar a ponto de ter sido historicamente possível elaborar as violências de gênero como "naturais" e não como construções socioculturais, criadas e valorizadas em determinadas sociedades. (SCHRAIBER et al, 2005).

Este estudo utilizou como referência à seguinte definição a respeito da "cultura do estupro":

(...)Cultura do estupro é um conjunto complexo de crenças que encorajam agressões sexuais masculinas e sustentam a violência contra a mulher. É uma organização social em que a violência é vista como sensual e a sexualidade como violenta. Na cultura do estupro a mulher percebe a ameaça da violência como um continuum que vai desde comentários sexuais até o contato sexual e o estupro. A cultura do estupro tolera o terrorismo físico e emocional contra a mulher como norma. (...) Em uma cultura do estupro tanto homens como mulheres assumem que a violência sexual é um fato da vida, inevitável (BUCHWALD, FLETCHER e ROTH,1993).

Rost e Vieira (2015) afirmam que a noção de cultura do estupro popularizou-se recentemente no país, numa sociedade que "não apenas tolera a violência sexual contra a mulher, como também a incentiva e a legitima". Safiotti também corrobora essa afirmação: "a questão se situa na tolerância e até no incentivo da sociedade para que os homens exerçam sua força-potência-dominação contra as mulheres” (SAFFIOTI, 2011,p. 75).

Ao analisar a reprodução e a variação de práticas culturais, Dittrich (2004) levanta o questionamento sobre o que levaria os integrantes de uma determinada geração em uma dada cultura a transmitirem as práticas dessa cultura às gerações futuras.

Práticas culturais são transmitidas entre gerações porque aqueles que as transmitem são reforçados por fazê-lo. O reforço pode ser direto (através do comportamento daquele(s) para o(s) qual(is) a prática é transmitida) ou indireto (através de agências governamentais, educacionais, religiosas, etc. ou de outras formas de reforço social dos comportamentos envolvidos na transmissão da prática). (DITTRICH, 2004, p. 161).

Contextos violentos são uma realidade frequente no Brasil e no mundo, frente a isso, Schraiber e colaboradores (2005) levantam questionamentos como: Por que tantas mulheres se envolvem e permanecem em relações permeadas de violência? Sem admitir respostas simples ou descontextualizadas, os autores afirmam que as escolhas de cada sujeito dependem não apenas da sua consciência e vontade individual, mas da cultura, da situação social, do acesso aos serviços e da opinião da família, dos amigos e da comunidade 
em que vive. Suas conclusões apontam que a oferta de serviços seguramente potencializa a efetivação dos direitos, o que favorece a percepção da violência como injustiça e a legitimidade de seu enfrentamento, com alternativas concretas de ação.

Segundo Bridges e colaboradores (2010) práticas largamente difundidas em nossa cultura e que fazem parte dessas várias contingências citadas acima associam diretamente sexo e violência por meio da indústria da pornografia e estão particularmente ligadas à educação sexual dos homens em nossa sociedade. Os autores analisaram 304 cenas de pornografia da internet e calcularam que $88,2 \%$ das cenas possuíam algum tipo de agressão ou violência física e 48,7\% possuíam violência verbal. Na maioria absoluta das cenas, a violência de homens é dirigida às mulheres. Generalizações dessas associações entre sexo e violência são frequentes e fazem parte também das classes de comportamentos classificados como Cultura do Estupro.

\section{A CONCEPÇÃo dA CULTURA do ESTUPRo E A ViolênCIA CONTRA A MULHER}

Em seu estudo histórico sobre a construção do estupro como fenômeno social na França, Vigarello (1998) correlaciona a recente visibilidade das diversas categorias de violência sexual ao imperceptível surgimento de uma visão do sujeito e da intimidade. A modificação da percepção da violência, tida agora como crime, focaliza atos até então desprezados. Esse novo modo de olhar implica uma mudança na relação social entre homens e mulheres e na abordagem da situação da violência sexual, onde a mulher busca sustentar uma posição de sujeito (e não de objeto) nas relações que vivencia.

Minayo (2004; 2007) aponta que a violência é um fenômeno eminentemente histórico, humano e social pelo seu caráter relacional, com múltiplas causas e significados, o que o torna complexo em sua origem e manifestações. Por isso, ela não pode ser analisada nem tratada fora da sociedade que a produz em sua "especificidade interna" e em sua "particularidade histórica". Ao tratar das diferentes formas de violência que persistem no tempo e se estendem por quase todas as sociedades, a autora aborda a violência de gênero, como "naturalizada", ou seja, seria como se, ao cometê-la, a pessoa julgasse que estava fazendo algo normal, o que se configura como modalidade de "violência cultural", com jeitos próprios e típicos de pensar, sentir e agir.

Para Pasinato (2011), a violência contra as mulheres é universal e estrutural, e se fundamenta no patriarcado. A autora considera a morte de uma mulher como a forma mais extrema de um continuum de atos de violência consequentes de um padrão cultural que é 
aprendido e transmitido por várias gerações, sendo, ao mesmo tempo, resultado da desigualdade de poder entre homens e mulheres e condição para a manutenção dessa desigualdade.

Minayo (2004) aborda a violência contra as mulheres e sua interface com a saúde e lança luz à questão do sexo forçado na conjugalidade. A autora reconhece essa violência como "objeto" do setor saúde, devido à concepção ampliada de saúde e ao impacto provocado na qualidade de vida dessas mulheres.

As mulheres experimentam vários tipos de violência que podem ser cometidos por parceiros ou ex-parceiros, familiares, amigos, conhecidos ou estranhos e até por instituições públicas ou pelo Estado. Entre parceiros íntimos é comum à alegação "perdi o controle" e a suposição de uma falta de domínio emocional "como um homem teria". Tal comportamento infantiliza a mulher como quem deve ser ensinada a "comportar-se". As mulheres que experimentam tais situações nem sempre percebem essa vivência como uma violência. Tendem a assumir que teriam desencadeado as agressões e humilhações, por conta de um comportamento pessoal seu, ou pela inadequação de todas as mulheres que teriam uma "natureza provocadora". A violência não aparece como tal, encontra-se invisível. Quanto mais visível se tornar a "violência que desencadeia sofrimentos e danos à saúde, mais eficaz será a ação assistencial” (SCHRAIBER et al, 2005, p. 94).

Os avanços no reconhecimento da legitimidade e da gravidade dessas questões levaram consequentemente a uma resposta do Estado, que o fez, legal e formalmente, com a criação das Delegacias Especiais de Atendimento às Mulheres (DEAM'S). A característica marcante da DEAM seria a possibilidade de uma escuta e de um olhar distinto, por meio de delegadas e agentes policiais mulheres capacitadas em relação às especificidades que caracterizam a violência contra a mulher, bem como a compreensão dos contextos em que ocorrem. Um avanço mais recente apontado pela autora foi a Lei $\mathrm{n}$. 11.340/2006, cunhada "Lei Maria da Penha", voltada a erradicação, coibição, punição e prevenção da violência doméstica e intrafamiliar (BANDEIRA, 2014).

Com a grande recorrência de atos violentos, nota-se que a ordem tradicional vem se ressignificando, remodelando os padrões e os valores sexistas sem eliminá-los. Com isso, não há ruptura significativa nas estruturas que ordenam e regem as hierarquias e os papéis femininos e masculinos na esfera familiar, que ainda são projetadas a outras searas e processadas em outros espaços institucionais. Sentimentos apreendidos socioculturalmente, a esperança na modificação do comportamento do agressor; o medo de represálias e novas agressões; o medo de perder a guarda dos filhos; a censura da família e da comunidade, a 
dependência econômica e afetiva, dentre outras adversidades dificultam o rompimento de relações abusivas (BANDEIRA, 2014).

\section{A ODISSÉIA EM TORNO DA CRIMINALIZAÇÃO DA VIOLÊNCIA SEXUAL CONTRA AS MULHERES}

A violência sexual deve ser entendida como uma violação aos direitos individuais, mas nem sempre foi assim. Segundo Vigarello (1998), os crimes costumavam ser estudados do ponto de vista do tutor legal delas, ou seja, não se tratava de uma agressão ao corpo da mulher, a ela enquanto pessoa, mas sim contra a propriedade do seu responsável legal geralmente o pai ou o marido. Somente no fim do século XVIII, na Declaração dos Direitos Humanos, lida como prefácio à Constituição de 1789, a vítima é tida como sujeito e o dano recai sobre seu ser privado e não sobre tutores.

No século XX houve uma aproximação com as ciências sociais focada em valores sociais e comportamentos grupais. Rost e Vieira (2015) destacam, que, em 1971, um dos primeiros trabalhos com esse enfoque a partir da noção de violência sexual foi o de Menachem Amir, um estudo sobre o estupro na cidade de Filadélfia, nos Estados Unidos. Os resultados do sociólogo revelaram que mais de 70\% dos estupros eram planejados, uma constatação importante que quebrou o mito que eles seriam oriundos de emoções reprimidas ou desejos incontroláveis. O mesmo estudo também foi importante para desmistificar o comportamento de risco, como roupas ou horário em que a mulher estava na rua uma vez que se constatou que mais da metade dos estupros aconteciam na casa da vítima.

O final da década de setenta e o início da década de oitenta foi significativo na luta contra a violência machista no Brasil. Datam desse período inúmeras manifestações em diversos lugares do país que protestavam contra o assassinato de mulheres, por meio de campanhas, vigílias nas portas dos tribunais e caminhadas nas ruas, com repercussão também na mídia impressa e televisiva (BRAZÃO e OLIVEIRA, 2010). A respeito da formação do "lobby do batom" e da "Carta das Mulheres", Machado (2016) destaca que na época da Constituinte o direito à "igualdade de gênero" passou a constar na Constituição da República Federativa do Brasil de 1988 graças à pressão do movimento feminista e do contexto político favorável aos avanços da democracia e do "progresso social".

Em relação aos avanços nas políticas para o enfrentamento desse problema, uma visibilidade maior nos anos de 1990 permitiu que a demanda por políticas públicas nesse campo finalmente entrasse para a agenda (ROST e VIEIRA, 2015). Machado (2016) 
salienta, porém, algumas especificidades do movimento brasileiro. A autora aponta uma diferenciação com os movimentos americano e francês onde menciona que, no Brasil, a reivindicação pela liberdade sexual, apesar de também existir, era menor que a luta pela defesa da vida das mulheres, pelo direito a sobrevivência. Ela também acrescenta que a referida década se caracterizou pela produção de formatos organizacionais não governamentais capazes de dar respostas positivas no diálogo com o Estado.

Segundo Machado (2016), enquanto os anos noventa representaram uma forte relação e articulação entre os movimentos feministas e as instituições intergovernamentais, o que levou a consolidação dos direitos das mulheres. O governo Collor produziu uma grave crise nessas relações, fato que fora superado parcialmente no governo de Fernando Henrique Cardoso e que ganhou mais destaque durante o governo Lula, num retorno à pauta como nenhum outro governo se propusera até então:

Foi constituída a Secretaria Especial de Políticas para as Mulheres (SPM) vinculada diretamente ao Gabinete Civil, chefiada por secretária com status de ministra. Status que implicava autonomia orçamentária e reconhecia a necessidade de produção de políticas públicas específicas, e de coordenação e incentivo de ações nos demais órgãos governamentais, com vistas à transversalidade das questões sociais de gênero. O status de ministra e o vínculo direto da SPM com o Gabinete Civil se manteve até outubro de 2015 no segundo governo Dilma (MACHADO, 2016, p. $12-$ 13).

A mudança ocorreu devido a uma crise política e econômica, frente a um Congresso sensível a pautas conservadoras. A fragilidade política do Executivo, aumentaram as incertezas face à pouca autonomia de se opor a essas forças neoconsevadoras que ameaçavam as conquistas alcançadas até ali, tais como políticas públicas transversais para mulheres nas diretrizes e ações dos diversos Ministérios Federais. O cenário apresentava e ainda apresenta um confronto entre Estado Laico e Estado "Moral", o segundo inscrito em moralidades religiosas e sectárias (MACHADO, 2016).

Machado (2016) aponta o confronto entre o neoconservadorismo e a educação pela igualdade de gênero, a educação não sexista. Ela relata os incidentes de recolhimento de vídeos educativos produzidos por demanda do Ministério da Educação e de retirada dos objetivos de enfrentamento à desigualdade de gênero no Plano Nacional de Educação. Os argumentos entre os que entendem que a questão de gênero seria danosa ao processo educacional baseiam-se na defesa de "valores tradicionais da família brasileira" e no 
entendimento como sendo "virtuosa" a divisão naturalizada dos papéis sociais, tradição essa permeada por severas desigualdades e discriminações.

No bojo desta contextualização sócio-histórica do cenário atual, com ameaças e tentativas de desmantelização do Sistema único de Saúde(SUS), consideramos a importância da influência de processos sociais e históricos sobre a construção das identidades/subjetividades e dos processos relacionais. Nesse sentido, a análise da existência de articulações entre problematizações feministas/de gênero e programas de prevenção e promoção de saúde, ressalta a proposta da clínica ampliada como estratégia preventiva.

\section{Discussão}

Embora a compreensão de acontecimentos sociais dentro da visão de gênero já tenha algum acúmulo histórico, sua aceitação não é fácil mesmo entre as mulheres. Admitir e trabalhar com essa realidade desigual não é fácil nem agradável. Requer uma qualidade crítica difícil de obter por envolver um movimento contracultural que questione os valores que situam a mulher numa posição subordinada. A ausência dessa crítica reforça a violência vivida por certas mulheres, como problemas de uma esfera privada, delas próprias, ou pior: como problema nenhum (SCHRAIBER et al, 2005).

Falta o reconhecimento de certos acontecimentos da sociedade como um todo, para os quais cabem ações públicas e políticas sociais adequadas, como programas de esclarecimento, campanhas antiviolência, além de programas de apoio em instituições com ações de caráter interdisciplinar e intersetorial que componham redes de várias assistências: à saúde, à segurança pública e pessoal, à justiça e ao bem-estar social. O acesso a esses serviços é fundamental para garantir formas de solução para esse problema e a responsabilidade de efetivar essas políticas é do Estado. Sem isso, não haverá respeito à liberdade e à dignidade individual (SCHRAIBER et al, 2005).

O Ministério da Saúde situa a violência no centro da discussão como fenômeno a ser compreendido, diagnosticado e tratado adequadamente pelos profissionais e serviços de saúde em seus aspectos preventivos. Além de inseri-lo no campo da promoção de saúde, como direito social, o que é uma responsabilidade primordial das políticas governamentais (ESCORSIM, 2014).

Murta, Del Prette e Del Prette (2010) reconhecem o desenvolvimento de fatores de proteção, recursos e competências como base da prevenção primária em saúde mental e afirmam que as atividades de pesquisa em prevenção devem ser orientadas pela 
identificação e fortalecimento dos fatores de proteção e a minimização de estressores como: a violência contra a mulher, o sexismo, o heterossexismo e a homofobia. Esses estressores são, pois, alguns dos fatores que apresentam risco para a saúde mental. Os autores propõem a criação e adequada implementação de políticas públicas que promovam a equidade de gênero para melhorar a saúde mental tanto de homens quanto de mulheres.

O estudo feito por Zanello e Bukowitz (2011), que objetivava analisar os discursos dos pacientes psiquiatrizados, pela ótica das relações de gênero, mostrou que valores e estereótipos de gênero que são partilhados culturalmente também estão fortemente presentes na experiência de sofrimento psíquico grave desses pacientes. As autoras ressaltam a importância de repensar formas de intervenção, de modo que valores engendrados também possam ser utilizados como ferramentas de intervenção, o que pode auxiliar ações terapêuticas e fazer parte das estratégias interventivas devido ao sofrimento psíquico a que podem levar essas questões de gênero.

Com base no trabalho de Abreu e Murta (2012) sobre o "estado da arte da pesquisa nacional em prevenção em saúde mental", Alves (2013) desenvolveu uma revisão sistemática com o objetivo de analisar se os programas preventivos em saúde mental consideravam questões de gênero ou faziam referência à perspectiva feminista. A autora constatou que nenhuma das publicações fez uma discussão de gênero ou mencionou essa categoria como importante. Nenhuma das literaturas consultadas por eles fez menção ou apontou as implicações das relações sociais de gênero para a saúde mental. Dos 25 artigos estudados, oito mencionavam a palavra gênero, mas usando-a apenas como sinônimo de sexo. O que mostra o quanto a Psicologia carece dessas discussões, pois revelam a influência dessas questões relacionais de gênero e de outros fatores sociais em dimensões de diagnóstico, medicalização e prevenção em saúde mental.

Em estudo semelhante, Backes (2007) realizou um levantamento dos trabalhos de Educação Popular apresentados em evento da Associação Nacional de Pós-graduação e Pesquisa em Educação entre 2002 e 2006. O autor constatou que, entre os 66 textos encontrados, apenas cinco fizeram alguma referência a gênero, o que mostra uma abordagem marginal e incipiente. Backes enxerga o resultado encontrado como consequência das relações de poder existentes tanto no interior do grupo pesquisado como na sociedade de forma mais ampla. Ele também registra uma curiosidade a respeito do grupo de trabalho da educação popular, que, apesar de ter grande afinidade com Paulo Freire (citado em 32 dos 66 trabalhos) não há sequer uma mínima menção à sua sugestão 
feita em seu livro Pedagogia da Esperança de considerar a dimensão de gênero, como importante para a leitura de mundo.

Ao tratar dos programas preventivos em saúde mental que envolvam a promoção da igualdade de gênero, Murta, Del Prette e Del Prette propõem:

Pode-se supor que o sexismo e o heterossexismo são enfraquecidos ou prevenidos a partir do desenvolvimento de habilidades que facilitem a adoção da perspectiva do outro (empatia), a desconstrução de estereótipos de gênero (pensamento crítico e relacionamento interpessoal), a aprendizagem de formas assertivas de negociar direitos (comunicação interpessoal), o enfrentamento saudável das próprias emoções desagradáveis, potencialmente presentes nas transições da adolescência (manejo de emoções), a análise de vantagens e desvantagens dos comportamentos de risco à saúde sexual e reprodutiva (tomada de decisão) e o uso de estratégias saudáveis para lidar com pressões pelos pares relacionadas aos papéis de gênero (resolução de problemas interpessoais) (MURTA, DEL PRETTEE \& DEL PRETTE, 2010, p. 81).

Alves (2013) alerta para a importância de modificar esse cenário de negligência a aspectos tão importantes nas propostas e estratégias preventivas em saúde mental.A autora indagou se elas não estariam, apenas, cumprindo com a finalidade inicial da psicologia de ajustar os indivíduos ao status quo aceito. Ela ainda acrescenta:

As práticas interventivas de tratamento (psicoterapias, intervenções psicológicas comunitárias, dentre outras) e prevenção em saúde mental devem assumir uma postura de considerar a importância das construções sociais de gênero, assim como fatores culturais, pessoais, sociais, relacionais, biológicos, econômicos e históricos para o processo de saúde mental e sofrimento psíquico de homens e mulheres. Ignorar esses fatores pode resultar em uma prática violenta da psicologia, pois corre o risco de continuar reafirmando lugares e experiências que causam sofrimento (ALVES, 2013, p. 109-110).

Escorsim (2014) situa a violência como problema de saúde coletiva, que deve ser objeto da política de saúde em duas dimensões: a primeira, na operacionalização das ações em saúde, com protocolos preventivos (primário, secundário e terciário), de capacitação continuada dos profissionais e da criação, ampliação e melhoria dos recursos e equipamentos referenciados do SUS. Na segunda dimensão, estariam englobadas as políticas de promoção de saúde, a articulação de vários ministérios e órgãos do governo, a fim de estimular conhecimentos, debates e ações sobre o tema em toda a sociedade.

A autora acrescenta que os caminhos a serem eleitos demandam construções coletivas de novas práticas e formas de expressão da cultura popular, com base no respeito à diversidade social e tolerância frente às diferenças de gênero. Isso significa ampliar o 
campo de atenção da violência como fenômeno social não restrito ao campo punitivo da segurança pública, como vem sendo tratada até o momento, mas como fenômeno construído sócio-historicamente, que está organicamente vinculado com as múltiplas expressões da questão social no bojo das relações econômico-sociais do desenvolvimento capitalista contemporâneo (ESCORSIM 2014).

Diante das considerações feitas, a problematização das questões de gênero bem como a desnaturalização dessas práticas culturais mostra-se urgente. O entendimento do Estupro como uma violência, uma violação grave dos direitos humanos leva a necessidade de discussões sobre cultura do estupro, sobre machismo, sobre misoginia e sobre cultura patriarcal, pois elas estão conectadas. Da mesma forma, o reconhecimento crítico de nossas práticas é indispensável.

\section{CONSIDERAÇÕES FINAIS}

Inicialmente, abordaram-se os conceitos de Práticas Culturais e Cultura do Estupro. Com base nesses referenciais teóricos e conceituais utilizados neste trabalho, constataram-se os seguintes pontos: (i)nossa cultura é permissiva em relação às práticas que permitem e reforçam a violência sexual contra as mulheres; (ii)esse tipo de violência é construída e determinada histórica e socialmente; (iii) existe um entrelaçamento entre a violência sexual contra a mulher com outras desigualdades como as de raça e de classe. Porém esse entrelaçamento normalmente é ofuscado por definições e valores herdados como inerentes a uma natureza feminina.

Ao articular o referencial teórico e conceitual com as análises obtidas dos programas de Promoção e Prevenção de Saúde também se demonstrou a ausência de problematizações de gênero nos mesmos. A constatação da incipiência dessa crítica nos resultados mostra o quanto a eles carecem dessas discussões, pois revela a influência dessas questões relacionais de gênero em dimensões de diagnóstico, medicalização e prevenção em saúde mental. $\mathrm{O}$ acesso a serviços norteados por essa crítica é fundamental para o avanço no enfrentamento a essa questão de saúde pública e a responsabilidade de efetivar essas políticas é do Estado. Sem isso, não haverá a ruptura necessária para que sejam garantidos os direitos relativos a respeito e liberdade das mulheres.

Tornou-se claro com esta pesquisa que o estuprador não é, via de regra, um sujeito portador de sofrimentos mentais. Haja vista a existência de uma enxurrada de dados que indicam a violência sexual contra as mulheres como instalada de forma estrutural em nossa sociedade. Ele é, sim, um indivíduo inserido numa cultura de dominação masculina, que 
enxerga as mulheres como propriedade dos homens, uma cultura que utiliza o sexo como uma relação de poder, de subjugação e de afirmação de virilidade. As pesquisas aqui apresentadas revelam, por exemplo, que mais de $70 \%$ dos estupros eram planejados e que mais da metade aconteciam na casa da vítima, dados importantes para quebrar o mito de que eles seriam oriundos de desejos incontroláveis, bem como para desmistificar os "comportamentos de risco" como roupas ou horários das mulheres nas ruas, que contribuíam para a responsabilização das vítimas.

Os achados do presente estudo levaram a uma reflexão da influência das questões de gênero no aprisionamento das mulheres dentro de normas restritas, impostas desde o início de sua socialização, que afetam seu modo d vida e permeiam de diferentes formas os processos de adoecimento. Também foi possível concluir que se faz necessário atentar aos padrões da desigualdade de gênero, de forma a não pleitear uma simples inclusão das mulheres, apenas com vistas à igualdade de acesso aos direitos e espaços, pois isso pode apoiar a reprodução das formas de marginalização existentes.

A valorização das diferenças, e não sua negação se mostra como um caminho mais assertivo na garantia da liberdade e do respeito para a afirmação das identidades dos indivíduos. Uma das maiores contribuições da Psicologia se situa exatamente nesse ponto, pois com sua teoria e prática embasada em evidências, permite estudar e intervir em práticas sociais associadas a experiências de sofrimento psíquico. Para tanto, porém, é preciso um reconhecimento crítico de sua prática.

Nesse sentido, recomenda-se novas pesquisas sobre a transmissão da cultura do estupro entre sucessivas gerações e as possíveis contribuições da psicologia no enfrentamento, bem como sobre a influência das relações de saber e poder do discurso colonial (construção de um saber) para legitimar a autoridade (um poder) do patriarcado sobre as mulheres. 


\section{REFERÊNCIAS}

ALVES, C. O. Psicologia e perspectiva feminista: produção de conhecimento, prática e programas de prevenção em saúde mental. Dissertação de Mestrado, Universidade de Brasília, Brasília/DF, 2013.

BACKES, J. L. Gênero e educação popular: uma leitura do GT da Anped. In: Anais do $16^{\circ}$ Congresso de Leitura do Brasil; Campinas, SP. Campinas: Unicamp; 2007.

BANDEIRA, L. A contribuição da crítica feminista à ciência. Estudos Feministas, Florianópolis, v. 16, n. 1, 2008.

BANDEIRA, L. M. Violência de gênero: a construção de um campo teórico e de investigação. Revista Sociedade e Estado, v.29, n. 2, Brasília, 2014.

BIROLI, F., MIGUEL, L. F. Gênero, raça, classe: opressões cruzadas e convergências na reprodução das desigualdades. Mediações, vol. 20, n 2. Londrina, 2015.

BOURDIEU, P. A dominação masculina. Rio de Janeiro: Bertrand Brasil, 2002.

BRAZÃO, A., OLIVEIRA, G. C. de. Quem ama não mata - Década de 70 e 80. Em: (org.). Violência contra as mulheres - uma história contada em décadas de luta,Brasília: CFEMEA: MDG3 , 2010.

BRIDGES, A. J., WOSNITZER, R., SCHARER, E., SUN, C., \& LIBERMAN, R. Agression and sexual behavior in best-selling pornography vídeos: A contente analysis update. Violence Against Women, 16(10), 1065-1085, 2010.

BUCHWALD, E.; FLETCHER, P. R.; ROTH, M. Transforming a Rape Culture.Minneapolis: Milkwood Editions, 1993.

COSTA, A. A. A. O movimento feminista no Brasil: dinâmicas de uma intervenção política. Gênero, v. 5, n.2, 2006.

DITTRICH, A. Behaviorismo radical, ética e política: Aspectos teóricos do compromisso social. Tese de doutorado, Universidade Federal de São Carlos, São Carlos /SP, 2004.

ESCORSIM. S. M. Violência de gênero e saúde coletiva: um debate necessário. Revista Katálysis. Florianópolis, v.17, n. 2, 2014.

FÓRUM BRASILEIRO DE SEGURANÇA PÚBLICA. (2019). Anuário Brasileiro de Segurança Pública. Disponível em: http://www.forumseguranca.org.br/wpcontent/uploads/2019/02/Infogra $\%$ CC $\% 81$ fico-vis $\%$ C3\%ADvel-e-invis $\%$ C3\%ADvel2.pdf. Acesso em: 02 Junho de 2019.

GERGEN, K. J. A crítica feminista da ciência e o desafio da epistemologia social. In: Mary McCanneyGergen. O pensamento feminista e a estrutura do conhecimento. Tradução de Ângela Melin, Rio de Janeiro: Rosa dos tempos: Edunb, 1993.

MACHADO, L.Z., Feminismos brasileiros nas relações com o Estado. Contextos e incertezas. Cadernos Pagu. Núcleo de Estudos de Gênero, Campinas, Unicamp - (47), 2016:e16471, 2016. 
MBEMBE, A. Necropolítica, unarevisión crítica. Em: GREGOR, H. C. M. (Org.). Estética y violencia: Necropolítica, militarización y vidas lloradas. México: UNAMMUAC, 2012.

MIGUEL, L. F., BIROLI, F. Feminismo e política: uma introdução. Boitempo Editorial. São Paulo, 2014.

MINAYO, M. C. S. A difícil e lenta entrada da violência na agenda do setor saúde. Caderno de Saúde Pública [online], Rio de Janeiro 2004. Disponível em: http://dx.doi.org/10.1590/S0102-311X2004000300001. Acesso em: 01 de Maio de 2019.

Recebido em 29 abr 2020.

Publicado em 08 mai 2020.

Psicóloga. Especialista em Direitos Humanos, Gênero e Sexualidade (ENSP/FIOCRUZ) http:/ / lattes.cnpq.br/8999005647898264; https://orcid.org/0000-0001-9144-9302

E-mail: biamazagao@hotmail.com

ii Psicóloga. Mestre em Psicologia Social (UFRJ/RJ). Doutora em Saúde Pública (ENSP/FIOCRUZ) http:/ / lattes.cnpq.br/1719649094428581; https://orcid.org/0000-0002-5891-5516

E-mail: lusanir.carvalho@uva.br 